\title{
Increased sensitivity to platinating agents and arsenite in human ovarian cancer by downregulation of ASNA1
}

\author{
OSKAR HEMMINGSSON, MIKAEL NÖJD, GAUTAM KAO and PETER NAREDI \\ Department of Surgical and Perioperative Sciences, Surgery, Umeå University, S-90185 Umeå, Sweden
}

Received March 23, 2009; Accepted May 29, 2009

DOI: 10.3892/or_00000511

\begin{abstract}
Platinating agents constitute the first line treatment for ovarian cancer but treatment failure is common because of intrinsic and acquired resistance. Cancer cells develop the RASP-phenotype (cross resistance against arsenite, antimonite and platinum) associated with decreased accumulation of cisplatin and arsenite. ASNA1 is a possible subunit of a transport system for cisplatin and arsenite due to homology to arsA, an ATPase in the E. coli ars-complex responsible for efflux of arsenite and antimonite. Eukaryotic ASNA1 is a targeting factor for membrane insertion of tail-anchored proteins involved in the secretory pathway and cellular stress responses. The purpose with this study was to evaluate if ASNA1 expression influenced cisplatin, carboplatin, oxaliplatin or arsenite sensitivity in ovarian cancer. Human ovarian cancer cell line 2008 was transfected with a sense or an antisense ASNA1 construct. ASNA1 downregulated and overexpressing clones were identified by Western blots. Cell growth and chemosensitivity was determined by the MTT assay. Downregulated ASNA1 expression was associated with retarded growth and increased sensitivity to cisplatin, carboplatin, oxaliplatin and arsenite whereas the cisplatin resistant 2008/ A overexpresses ASNA1. These observations support the hypothesis that ASNA1 is a target to overcome platinum resistance in ovarian cancer.
\end{abstract}

\section{Introduction}

Platinum based drugs are used to treat a variety of solid tumours. Cisplatin and carboplatin have been in clinical use for many years to treat ovarian, testis, bladder, head and neck cancers and small-cell and non-small cell lung cancer (1). Oxaliplatin has a broader spectrum of clinical use, also affecting colon cancer (2). Of clinical relevance is intrinsic resistance by many tumour types to platinating agents. In addition, the cytotoxicity is limited by emergence of resistance during treatment of originally sensitive cells. Knowledge

Correspondence to: Dr Oskar Hemmingsson, Department of Surgical and Perioperative Sciences, Surgery, Umeå University, S-90185 Umeå, Sweden

E-mail: oskar.hemmingsson@surgery.umu.se

Key words: ASNA1, ovarian cancer, cisplatin, carboplatin, oxaliplatin, drug resistance about how platinum is detoxified is important in order to understand how to circumvent resistance. One important mechanism for resistance is reduction of intracellular platinum levels (3). Cisplatin resistant cells exhibit not only a low platinum content, but also a decreased accumulation of arsenite (4). These cells are cross resistant to arsenite, antimonite and cisplatin, termed the RASP-phenotype (ㄹesistance to $\underline{\mathrm{As}} \mathrm{s} \underline{\mathrm{S}} b$ and $\underline{\mathrm{P}})(4,5)$. This suggests a common resistance mechanism that acts by either increased efflux or decreased influx of the drug.

Ion transporters are often conserved during evolution (6). In bacteria, the ars-operon is responsible for efflux of antimonite and arsenite. The Ars-complex consists of five subunits; two regulatory proteins, one reductase and an ATPase (ArsA) that acts in association with a channel protein (ArsB) to form an efflux pump (7). The ars-operon is conserved among prokaryotes while, in eukaryotes; there is an $\operatorname{ars} \mathrm{A}$ homologue in nearly every organism (8).

ASNA1, the human homologue of arsA (9) is an arsenite stimulated ATPase $(10,11)$ and is found in the cytosol, in the perinuclear region and in the nucleolus (12). Immunohistochemistry studies reveal ASNA1 expression in several types of normal tissues and cancers (13). Downregulation of ASNA1 results in growth arrest and increased arsenite sensitivity in Caenorhabditis elegans $(11,14)$, embryonic lethality in mice (15), decreased insulin secretion (14) and retarded growth and increased apoptosis in humans (16). An explanation for such a diverse set of functions may lie in recent reports showing that ASNA1 mediates ER membrane insertion of tailanchored proteins (17-19).

We have previously reported increased sensitivity to arsenite and cisplatin by downregulation of ASNA1 in a human melanoma cell line (16). Cisplatin and carboplatin are generally considered to share the same pharmacodynamic and pharmacokinetic pathways while oxaliplatin cytotoxicity and resistance is mediated by other mechanisms (20). In this study, we investigated whether altered ASNA1 levels affect the sensitivity not only to cisplatin and arsenite but also to carboplatin and oxaliplatin.

There is evidence for the involvement of copper transporters in cisplatin resistance (21-23). Moreover, disruption of the ASNA1 homologue arr4/GET3 in yeast results in increased sensitivity to copper (24). To evaluate if ASNA1 contributes to copper resistance we also determined the copper sensitivity in ASNA1 overexpressing and downregulated cells. 
Here we report that reduced ASNA1 expression in human ovarian cancer cells results in increased sensitivity to cisplatin, carboplatin, oxaliplatin and arsenite. In addition, cisplatin and arsenite resistant ovarian cancer cell line 2008/A overexpresses ASNA1. In this study we observe neither increased sensitivity nor resistance to zinc or copper by altering ASNA1 expression. This is consistent with the hypothesis that ASNA1 is involved in a pathway responsible for the RASP-phenotype and identifies ASNA1 as a target to overcome resistance.

\section{Materials and methods}

Cell culture. Human ovarian cancer cell line 2008 (25) and the cisplatin resistant subline 2008/A (4) were grown in RPMI-1640 (Invitrogen, Paisley, UK) supplemented with 5\% fetal bovine serum (FBS), termed complete medium. The medium for transfected cells containing a neomycin resistance gene was supplemented with $0.3 \mathrm{mg} / \mathrm{ml} \mathrm{G} 418$ (Invitrogen). Cells were grown in monolayer culture at $37^{\circ} \mathrm{C}$ in humidified air with $5 \% \mathrm{CO}_{2}$.

Plasmid transfection. The 2008 cells were transfected with the previously described pTarget-ASNAI-sense, pTargetASNA1-antisense and pTarget-empty vector plasmids (16) using lipofectamine reagent (Invitrogen). Briefly, cells were seeded on petri dishes and grown in complete medium until $70 \%$ confluency. Four micrograms of plasmid DNA and $30 \mu 1$ lipofectamine were mixed in $750 \mu 1$ serum-free medium and incubated $15 \mathrm{~min}$ in room temperature before addition to the cells. After $4 \mathrm{~h}$ incubation at $37^{\circ} \mathrm{C}, 5 \mathrm{ml}$ of medium containing $20 \%$ FBS was added. The next day the FBS-enriched medium was exchanged to complete medium supplemented with $1 \mathrm{mg} / \mathrm{ml} \mathrm{G} 418$. After 2-3 weeks, independent cell clones were randomly isolated and plated separately for clonal expansion in complete medium.

Immunoblotting. Exponentially growing cells were lysed in ice-cold buffer containing $10 \mathrm{mM}$ Tris- $\mathrm{HCl}$ (pH 7.4), $150 \mathrm{mM}$ $\mathrm{NaCl}, 5 \mathrm{nM}$ EDTA, $1 \%$ Triton, 5 mM DTT, $0.1 \mathrm{mM}$ PMSF and $1 \%$ protease inhibitor cocktail (Sigma, Stockholm, Sweden). The supernatant was collected after centrifugation at $14,000 \mathrm{rpm} 20 \mathrm{~min}$ at $4^{\circ} \mathrm{C}$. The total protein concentration of the lysates was determined using the DC Protein Assay (Biorad, Sundbyberg, Sweden). Thirty micrograms of total cellular protein was separated in 10\% SDS-PAGE gels and electrotransferred to immobilon-p membranes (Millipore, Sundbyberg, Sweden). After blocking in 5\% fat-free milk in $1 \mathrm{X}$ TBS, the membranes were incubated for $1 \mathrm{~h}$ with a primary rabbit anti-ASNA1 antibody (16) $(1: 2000,1 \mathrm{~h}$ at room temperature) (Agrisera, Vännäs, Sweden). After washing, the membranes were incubated for $30 \mathrm{~min}$ with a secondary horseradish peroxidase-conjugated donkey antirabbit antibody (Amersham Pharmacia Biotech, Uppsala, Sweden). The bound antibodies were visualized by chemiluminescence using the ECL-kit (Amersham Pharmacia Biotech). To confirm equal loading, membranes were stripped for $30 \mathrm{~min}$ at $50^{\circ} \mathrm{C}$ in a buffer containing $100 \mathrm{mM}$ betamercaptoetanol, 2\% SDS and $0.0625 \mathrm{M}$ Tris (pH 6.7), and then incubated with a primary monoclonal anti- $\beta$-actin antibody (Sigma) and a secondary horseradish peroxidase- conjugated sheep anti-mouse IgG antibody (Amersham Pharmacia Biotech), detected as described above. The bands were quantified using Quantity One 4.5.2 (basic) software (Biorad).

Cell growth assay. Ovarian cancer 2008 cells in suspension were stained by trypan blue and counted in a Bürkel chamber. Then, 1500 cells were seeded in $200 \mu \mathrm{l}$ complete medium on 96-well plates. The plates were incubated at $37^{\circ} \mathrm{C}$ in humidified air with $5 \% \mathrm{CO}_{2}$ for 24, 48, 72 and $96 \mathrm{~h}$. Anchorage-dependent cell growth was determined daily in triplicate wells by the MTT colorimetric growth assay (26) (Sigma). Twenty microliters of $5 \mathrm{mg} / \mathrm{ml}$ MTT was added to each well and incubated at $37^{\circ} \mathrm{C}$ for $4 \mathrm{~h}$. After removal of the medium, the dye crystals were dissolved in acidified isopropanol. The optical density was measured on an ELISA plate reader at $570 \mathrm{~nm}$ with background subtraction at 650 $\mathrm{nm}$. Each experiment was performed at least three times.

Chemosensitivity assay. To assess chemosensitivity, 3000 cells were seeded in $180 \mu \mathrm{l}$ complete medium in each well of 96-well plates. After $24 \mathrm{~h}$ in $\mathrm{CO}_{2}$-chamber, $20 \mu \mathrm{l}$ of test substance were added to reach final concentrations of $0-20 \mu \mathrm{M}$ sodium arsenite (Sigma), 0-1.0 $\mu \mathrm{g} / \mathrm{ml}$ cisplatin (Platinol ${ }^{\circledR}$, Bristol Myers Squibb AB, Sweden), 0-8.0 $\mu \mathrm{g} / \mathrm{ml}$ carboplatin (Paraplatin ${ }^{\circledR}$, Bristol Myers Squibb AB), 0-0.5 $\mu \mathrm{g} / \mathrm{ml}$ oxaliplatin (Eloxatin ${ }^{\circledR}$, Sanofi-Aventis AB, Sweden), 0-200 $\mu \mathrm{M}$ copper (II) sulphate (Merck, Germany) or 0-1.20 mM zinc chloride (Göteborgs termometerfabrik, Sweden). In each experiment, the assay was done in triplicate wells at each concentration. After $72 \mathrm{~h}$ incubation, cell number in each well was determined by the MTT assay as described above. Arsenite toxicity was measured after 48 h. Each experiment was performed at least three times. The concentration needed to reduce cellular population by $50 \%\left(\mathrm{IC}_{50}\right)$ was determined.

Statistical analysis. Results were expressed as mean \pm SEM. Results were compared by two-sided t-test. $\mathrm{P}<0.05$ was set as level of statistical significance. $\mathrm{IC}_{50}$-values and doubling times were calculated from the linear regression of the logarithmically transformed slope illustrating cell number vs. concentration and cell number vs. time. The relative sensitivity to each drug was determined by dividing the $\mathrm{IC}_{50}$-value with the $\mathrm{IC}_{50}$ value of the control 2008 wild-type and empty vectors. SPSS 16.0 for Mac OS X was used for statistical analysis.

\section{Results}

Generation of clones with altered ASNA1 expression. The ASNA1 sense construct was aimed at creating clones with increased ASNA1 expression. After transfection, 24 independent ovarian cancer cell line 2008 clones were randomly isolated and all grew well during clonal expansion. Two clones, s18 and s23, exhibited obvious overexpression of ASNA1. S18 had the highest ASNA1 expression, 300 $\pm 5.5 \%$ of wild-type $(\mathrm{p}<0.001)$ (Fig. 1). The ASNA1 antisense construct was set up to establish clones with decreased ASNA1 expression. Thirty-two independent clones were 

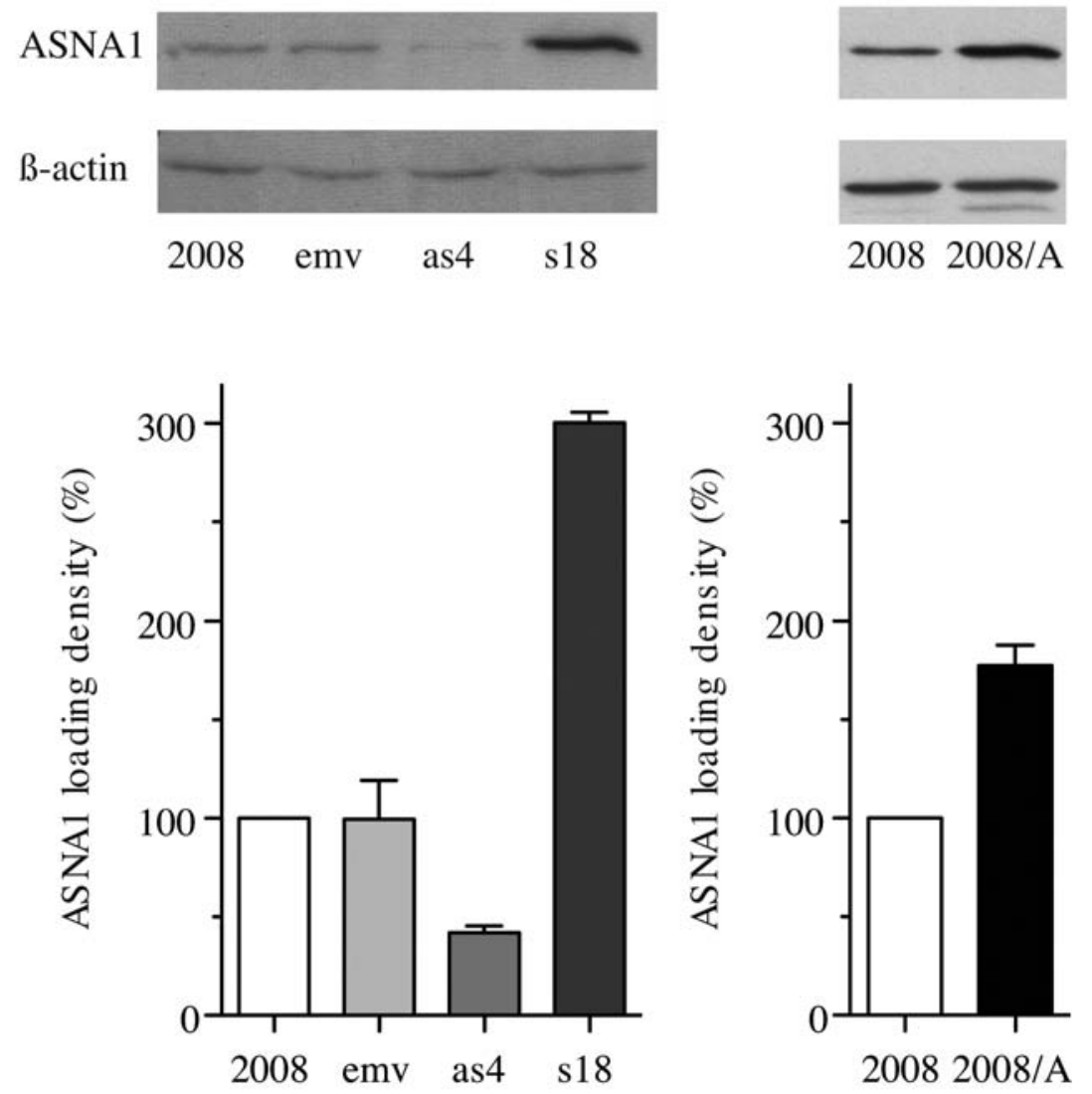

Figure 1. Western blots of total cellular lysates of ovarian cancer cell line 2008. ASNA1 was detected by a polyclonal anti-ASNA1 antibody at the 41 kDa level. B-actin was used as loading control. Band density was quantified by Quantity One 4.5.2 (Biorad). Bar diagram represent mean density \pm SEM from three representative blots. ASNA1 expression in wild-type 2008 and control empty vector transfectants (emv) was compared to 2008 transfected with an ASNA1-sense construct (s18) and 2008 transfected with an ASNA1-antisense construct (as4). ASNA-1 expression was also evaluated in the cisplatin resistant subline 2008/A (right panel).

randomly isolated. Six clones grew slowly and two clones died during clonal expansion. Three clones, as4, as9 and as28, had decreased levels of ASNA1 protein with as9 showing the lowest levels. However, as9 grew too slowly to be compared to other clones regarding chemosensitivity. As4 expressed $42 \pm 3.6 \%$ of wild-type ASNA1 levels $(\mathrm{p}<0.005)$ (Fig. 1), while as 28 had $71 \pm 4.9 \%$ of wild-type levels $(\mathrm{p}<0.05)$. All three ASNA1 downregulated clones grew slowly during clonal expansion. The empty vector construct was transfected into 2008 to establish control clones. Thirty-two clones were isolated and they expressed wild-type levels of ASNA1.

Retarded growth in ASNA1 downregulated cells. As noted, during clonal expansion the ASNA1 downregulated cells grew slowly compared to wild-type. We wished to quantify this growth defect by determining doubling time by the colorimetric MTT-assay. The doubling time for ASNA1 antisense clone as 4 was $140 \pm 5.5 \%$ of parental $2008(\mathrm{p}<0.05)$. Antisense clone as 28 also grew slowly compared to wild-type 2008 while ASNA1 overexpressing clone s18 and the empty vector control displayed similar doubling times (Table I).

Increased ASNA1 expression in cisplatin resistant 2008/A. A subline of ovarian cancer cell line 2008 was previously obtained by selection in cisplatin. The resulting clone, termed 2008/A, was 17-fold more resistant to cisplatin compared to
Table I. Doubling times in ovarian cancer cells with altered levels of ASNA1 expression.

\begin{tabular}{lcc}
\hline Cell & Doubling time $(\mathrm{h})$ & Doubling time (quotient) \\
\hline 2008 & $19.1 \pm 0.65$ & 1 \\
emv & $18.6 \pm 0.23$ & $0.98 \pm 0.034$ \\
as4 & $26.8 \pm 1.69$ & $1.40 \pm 0.055^{\mathrm{a}, \mathrm{c}}$ \\
as28 & $24.4 \pm 1.14$ & $1.28 \pm 0.023^{\mathrm{b}, \mathrm{c}}$ \\
s18 & $20.0 \pm 0.22$ & $1.05 \pm 0.025$ \\
\hline
\end{tabular}

Doubling times measured by the MTT assay. ASNA1 downregulated antisense clones (as4 and as28) grow slower than parental cell line 2008 , the control empty vector transfected subline (emv) and the ASNA1 overexpressing sense clone (s18). Data represent mean \pm SEM from three series. ${ }^{\mathrm{a}} \mathrm{p}<0.05$ compared to 2008 ; ${ }^{\mathrm{b}} \mathrm{p}<0.01$ compared to 2008 and ${ }^{c} \mathrm{p}<0.05$ compared to empty vector transfectants (emv).

wild-type and also resistant to antimonite and arsenite (4). To evaluate if ASNA1 is involved in RASP (Resistance to As, $\mathrm{Sb}$ and $\mathrm{Pt}$ ), the ASNA1 expression in 2008/A was measured. These cells displayed $177 \pm 10 \%$ ASNA1 expression compared to wild-type $(\mathrm{p}<0.05)$ as seen on Western blotting (Fig. 1). 

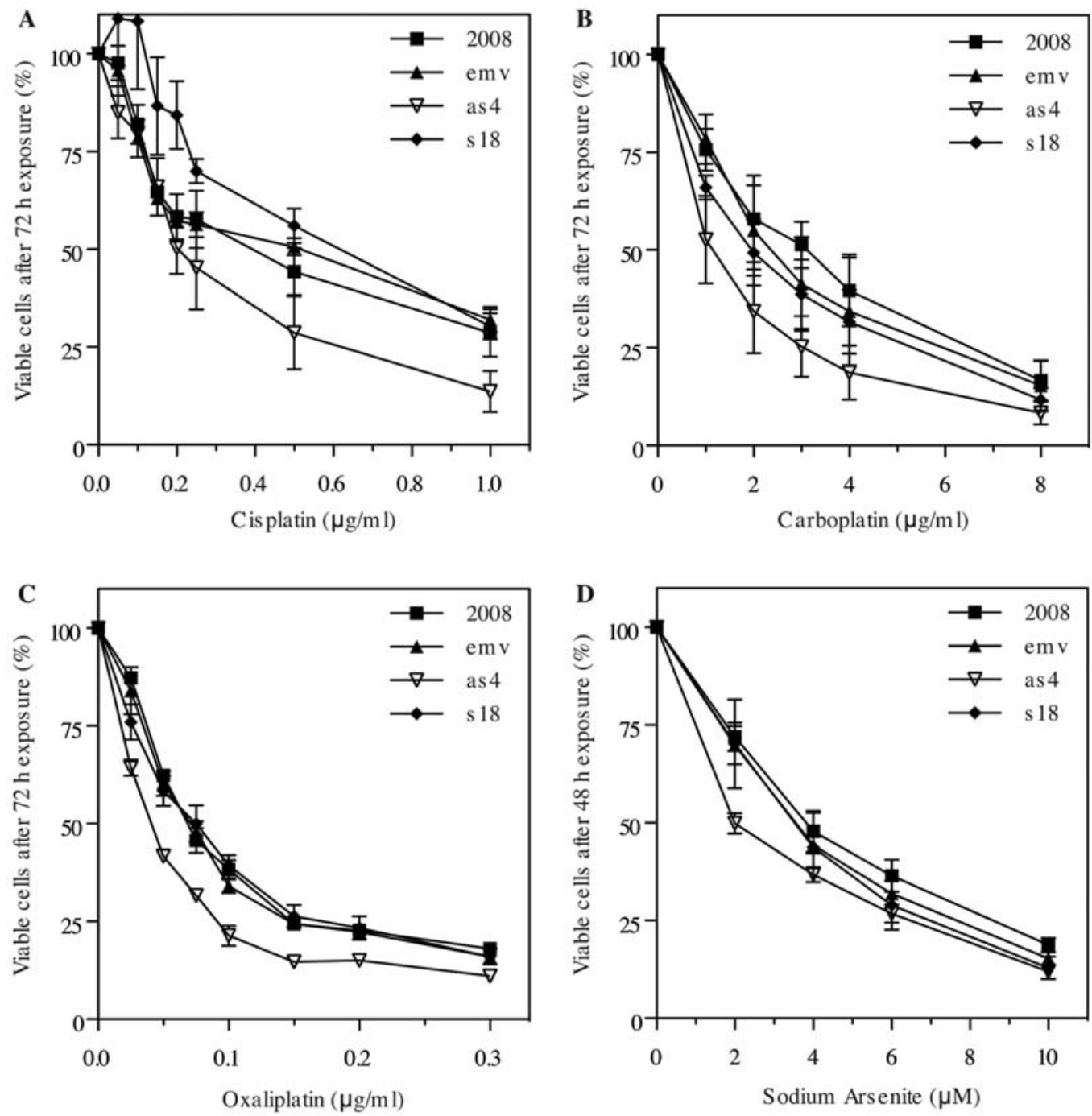

Figure 2. Chemosensitivity measured by the MTT assay in ovarian cancer cell line 2008. Wild-type 2008 and the control empty vector transfectants (emv) were compared to ASNA1 downregulated antisense clone (as4) and ASNA1 overexpressing sense clone (s18). Each data point represents mean percentage viable cells \pm SEM from three representative series. (A) Chemosensitivity to cisplatin after $72 \mathrm{~h}$ exposure. (B) Chemosensitivity to carboplatin after $72 \mathrm{~h}$ exposure. (C) Chemosensitivity to oxaliplatin after $72 \mathrm{~h}$ exposure. (D) Chemosensitivity to sodium arsenite after $48 \mathrm{~h}$ exposure.

ASNA1 is not the only requirement for the RASP phenotype. To evaluate if RASP is a result of increased ASNA1 expression in 2008/A, we measured chemosensitivity in ASNA1 overexpressing clone s18. Cells were subjected to a continuous 72 h exposure of cisplatin, carboplatin, oxaliplatin, copper (II) sulphate or zinc chloride or a $48 \mathrm{~h}$ exposure to sodium arsenite. Cytotoxicity was determined by the MTTassay. Overexpression of ASNA1 did not alter chemosensitivity to any test substance, compared with empty vector transfected cells or wild-type (Fig. 2A-D, Table II). Thus, although ASNA1 overexpression is induced in cisplatin resistant cells, ASNA1 expression alone is not a rate-limiting factor in a stipulated resistance mechanism.

Increased chemosensitivity in ASNA1 underexpressing clones. We could not detect any effect on copper sensitivity by increasing or decreasing ASNA1 expression (Table II). ASNA1 underexpressing cells were also as resistant as wild-type to zinc chloride. However, we found increased cisplatin sensitivity in the ASNA1 downregulated cells
(Fig. 2A). The cisplatin $\mathrm{IC}_{50}$ for antisense clone as 4 was $62.7 \pm 3.5 \%$ of parental $2008(\mathrm{p}<0.01)$. We detected increased sensitivity of the same magnitude to carboplatin and oxaliplatin in ASNA1 deficient as4 (Fig. 2B and C, Table II). We also observed increased sensitivity to arsenite (Fig. 2D and Table II) where $\mathrm{IC}_{50}$ was $72.0 \pm 6.4 \%$ of the wild-type value $(\mathrm{p}<0.05)$. Thus, downregulation of ASNA1 results in increased sensitivity to all three chemotherapeutic platinum compounds and arsenite. We note that the antisense clone as28 exhibited only a moderate decrease in ASNA1 expression. Nevertheless we observed a statistically significant increase in sensitivity to arsenite, cisplatin and carboplatin in as 28 compared to parental 2008 or empty vector transfected 2008 (Table II).

\section{Discussion}

In this study on ovarian carcinoma we demonstrate retarded growth and increased sensitivity to three platinum based drugs: cisplatin, carboplatin and oxaliplatin and arsenite by 
Table II. Chemosensitivity in ovarian cancer cells with altered levels of ASNA1 expression.

A. Platinum sensitivity measured by the MTT assay in ovarian cancer cell line 2008 .

\begin{tabular}{|c|c|c|c|c|c|c|}
\hline \multirow{2}{*}{ Cell } & \multicolumn{2}{|c|}{ Cisplatin $\mathrm{IC}_{50}$} & \multicolumn{2}{|c|}{ Carboplatin $\mathrm{IC}_{50}$} & \multicolumn{2}{|c|}{ Oxaliplatin $\mathrm{IC}_{50}$} \\
\hline & $(\mu \mathrm{g} / \mathrm{ml})$ & Quotient & $(\mu \mathrm{g} / \mathrm{ml})$ & Quotient & $(\mu \mathrm{g} / \mathrm{ml})$ & Quotient \\
\hline 2008 & $0.45 \pm 0.11$ & 1 & $3.11 \pm 0.91$ & 1 & $0.073 \pm 0.001$ & 1 \\
\hline emv & $0.45 \pm 0.06$ & $1.07 \pm 0.12$ & $2.93 \pm 1.14$ & $0.89 \pm 0.10$ & $0.071 \pm 0.004$ & $0.96 \pm 0.06$ \\
\hline as4 & $0.29 \pm 0.08$ & $0.63 \pm 0.03^{\mathrm{b}}$ & $1.44 \pm 0.50$ & $0.45 \pm 0.05^{\mathrm{b}, \mathrm{d}}$ & $0.044 \pm 0.002$ & $0.60 \pm 0.03^{b, d}$ \\
\hline as 28 & $0.26 \pm 0.05$ & $0.60 \pm 0.066^{\mathrm{a}, \mathrm{c}}$ & $1.12 \pm 0.24$ & $0.38 \pm 0.08^{\mathrm{a}, \mathrm{c}}$ & $0.073 \pm 0.007$ & $0.99 \pm 0.10$ \\
\hline s18 & $0.59 \pm 0.06$ & $1.46 \pm 0.34$ & $2.24 \pm 0.49$ & $0.76 \pm 0.15$ & $0.074 \pm 0.007$ & $1.01 \pm 0.09$ \\
\hline
\end{tabular}

B. Chemosensitivity measured by the MTT assay in ovarian cancer cell line 2008.

\begin{tabular}{|c|c|c|c|c|c|c|}
\hline \multirow{2}{*}{ Cell } & \multicolumn{2}{|c|}{ Sodium arsenite $\mathrm{IC}_{50}$} & \multicolumn{2}{|c|}{ Zinc chloride $\mathrm{IC}_{50}$} & \multicolumn{2}{|c|}{ Copper (II) sulphate $\mathrm{IC}_{50}$} \\
\hline & $(\mu \mathrm{M})$ & Quotient & $(\mathrm{mM})$ & Quotient & $(\mu \mathrm{M})$ & Quotient \\
\hline 2008 & $3.89 \pm 0.29$ & 1 & $0.61 \pm 0.094$ & $1^{\mathrm{d}}$ & $57.2 \pm 5.0$ & 1 \\
\hline emv & $3.61 \pm 0.25$ & $0.95 \pm 0.14$ & $0.57 \pm 0.090$ & $0.94 \pm 0.00^{\mathrm{b}}$ & $56.1 \pm 8.8$ & $1.02 \pm 0.25$ \\
\hline as4 & $2.77 \pm 0.16$ & $0.72 \pm 0,06^{\mathrm{a}}$ & $0.54 \pm 0.046$ & $0.92 \pm 0.10$ & $59.1 \pm 6.1$ & $1.05 \pm 0.15$ \\
\hline as 28 & $2.25 \pm 0.13$ & $0.58 \pm 0.06^{\mathrm{a}, \mathrm{d}}$ & nd & nd & $45.2 \pm 4.1$ & $0.82 \pm 0.15$ \\
\hline s18 & $3.53 \pm 0.81$ & $0.91 \pm 0.18$ & $0.63 \pm 0.052$ & $1.08 \pm 0.15$ & $55.6 \pm 4.2$ & $0.99 \pm 0.11$ \\
\hline
\end{tabular}

A. $\mathrm{IC}_{50}$, the inhibitory concentration needed to reduce the cell population growth by $50 \%$, was determined by the MTT assay after $72 \mathrm{~h}$ exposure to cisplatin, carboplatin or oxaliplatin. ASNA1 downregulated antisense clones (as 4 and as28) were more sensitive to platinating agents than wild-type 2008, the control empty vector transfectants (emv) and ASNA1 overexpressing sense clone (s18). Data represent mean $\pm \mathrm{SEM}$ from three representative series. $\mathrm{B}$. $\mathrm{IC}_{50}$ values after $48 \mathrm{~h}$ exposure to sodium arsenite or $72 \mathrm{~h}$ exposure to zinc chloride or copper (II) sulphate. ASNA1 downregulated antisense clones (as4 and as28) were more sensitive to arsenite than wild-type 2008, the control empty vector transfectants (emv) and ASNA1 overexpressing sense clone (s18). Data represent mean \pm SEM from three representative series. ${ }^{\mathrm{a}} \mathrm{p}<0.05$ compared to $2008 ;{ }^{\mathrm{b}} \mathrm{p}<0.01$ compared to $2008 ;{ }^{\mathrm{c}} \mathrm{p}<0.05$ compared to emv and ${ }^{\mathrm{d}} \mathrm{p}<0.01$ compared to emv. nd, not done.

antisense blockage of ASNA1. In addition, a cisplatin resistant subline of ovarian carcinoma overexpresses ASNA1. This confirms earlier observations from human malignant melanoma T289 cells where ASNA1 downregulation resulted in increased sensitivity to arsenite and cisplatin, retarded growth and increased apoptosis (16). The cisplatin and arsenite hypersensitivity due to ASNA1 deficiency is of the same magnitude in ovarian carcinoma and malignant melanoma.

Two previous observations resulted in the hypothesis that ASNA1 might be involved in arsenite and platinum resistance. First, ASNA1 is the human homologue of Escherichia coli ArsA, an ATPase responsible for efflux of arsenite and antimonite. ASNA1 and ArsA are both arsenite stimulated ATPases and share a NTP-binding motif $(9,10,27)$. Further, ASNA1 homologues in Saccharomyces cerevisiae and $C$. elegans have a conserved function in arsenite and antimonite resistance $(11,24)$. Secondly, tumour cells display the RASPphenotype constituted by cross resistance between arsenite, antimonite and cisplatin (5). RASP is associated with impaired accumulation of arsenite and the cisplatin analogue $\left[\mathrm{H}^{3}\right] \mathrm{DEP}$, indicating that an alteration in a transport mechanism may be the basis of this phenotype (4).

Bacterial ArsA acts in association with the transmembrane channel protein ArsB but there are no reported ArsB homologues in mammals (8). Instead, eukaryotic ASNA1 targets tail-anchored (TA) proteins for insertion into the ER membrane (17-19). TA-proteins are involved in several central pathways necessary for normal cellular function. Consequently, downregulation of ASNA1 results in disparate phenotypes such as changed cellular morphology, decreased insulin secretion, retarded growth, increased apoptosis and increased chemosensitivity $(14,16)$. Notably, ASNA1 deficient cells do not seem generally hypersensitive to stress since they are as resistant as wild-type to zinc chloride and other toxic metals beside antimonite, arsenite and platinum $(11,16)$. The observation that the ATPase activity of ASNA1 is stimulated by arsenite $(10,11)$ lets us speculate that cells exposed to arsenite or platinum have increased activity of ASNA1, potentially triggering a subset of TA-proteins important for resistance to the toxic metal.

SNARE proteins are TA-proteins controlling fusion of transport vesicles and cellular membranes (28). Vesicular efflux of cisplatin has been previously reported (29) and further studies are needed to clarify if ASNA1 participates in such a pathway.

Another important group of TA-proteins is the Bcl-2 family, which regulates apoptosis (30). Decreased ASNA1 expression results in increased apoptosis (16) and antiapoptotic Bcl-2 is upregulated in cisplatin resistant cells, inhibiting the DNA-damage signal and thus cell death (3). Cisplatin can also induce apoptosis and ER stress independently of DNA damage (31). Recent reports state that ASNA1 mediates an 
ER stress response by integration of the tail-anchored stressassociated endoplasmatic reticulum protein 1 (SERP1) into the ER (19). Interestingly, SERP1 knock-out mice demonstrate growth retardation, increased mortality and impaired insulin response on glucose stimulation (32), phenotypes that are similar to those seen in cell lines with decreased ASNA1 expression $(14,16)$.

Several reports reveal a link between cisplatin resistance and the copper transporters CTR1, ATP7A and ATP7B $(22,23)$. The $S$. cerevisiae ASNA1 homologue Arr4/GET3 interacts with transport protein Gef1 when copper is available and copper-mediated redox stress changes the conformation of Arr4/GET3 (33). Disruption of arr4/GET3 results in increased sensitivity to copper (24). Loss of several TA-proteins, possibly targeted by ASNA1, also results in hypersensitivity to copper (17). If ASNA1 would interact with copper transporters, one would expect that altered ASNA1 expression would have had an effect on copper sensitivity. However, in this study, changes in the level of ASNA1 expression did not influence copper cytotoxicity. It is possible that a small difference in sensitivity might be hidden in this setting and cells selected or transfected for copper resistance are reported to exhibit larger changes in cisplatin sensitivity than copper sensitivity (21). Thus, an association between ASNA1 and copper transporters cannot be excluded.

Clinical use in advanced colon cancer separates oxaliplatin from earlier generations of platinum drugs (2). Both cisplatin and oxaliplatin form DNA adducts but these are not detected by the same damage-recognition proteins, resulting in different clinical responses (34). Deficient DNA mismatch repair results in cisplatin resistance but does not affect oxaliplatin cytotoxicity (35). The moderate ASNA1 downregulation in antisense clone as 28 does not result in oxaliplatin hypersensitivity. Nevertheless, ASNA1 downregulation to $42 \%$ in as4 increases the sensitivity to cisplatin, carboplatin and oxaliplatin, indicating a general role for ASNA1 in platinum resistance.

ASNA1 overexpression did not result in platinum or arsenite resistance in this study nor in a malignant melanoma cell line (16). This is consistent with the hypothesis that ASNA1 acts as a subunit in a pathway where at least one other unit is required to confer resistance. Cisplatin resistant cell lines 2008/A and malignant melanoma T289/DDP (16), express elevated levels of ASNA1, probably together with a so far unknown target for ASNA1. Nevertheless, downregulation of only ASNA1 results in increased chemosensitivity, indicating that ASNA1 is the limiting factor to increase platinum susceptibility through this stipulated pathway.

It has not been possible to knock down the ASNA1 expression below approximately $40 \%$ of wild-type expression. ASNA1 underexpressing antisense clones as 4 and as 28 grew significantly slower compared to wild-type and as 9 grew too slowly to be assessed in chemosensitivity assays. We have reported similar growth defects in ASNA1 deficient human melanoma T289 cells (16). Observations in C. elegans nematodes reveal growth arrest in the first larval stage in ASNA1 depleted nematodes (14). Knock-out of ASNAI in mouse is embryonic lethal (15). Thus, we suggest that human cells need a basal level of ASNA1 for survival.
In conclusion, downregulation of ASNA1 results in retarded growth and increased sensitivity to cisplatin, carboplatin, oxaliplatin and arsenite in ovarian cancer. These observations support the hypothesis that ASNA1 is a target to overcome platinum resistance in ovarian cancer.

\section{Acknowledgements}

This study was supported by The Swedish Cancer Society (CAN2007/901), the Cancer Research Foundation in Northern Sweden, J.C. Kempe memorial foundation scholarship fund, the County council of Västernorrland and Västerbottens county council (ALF-means). We thank Anette Berglund, Christina Lundin, Eva-Maj Hägglöf, Maria Still and Youyi Zhang for technical assistance.

\section{References}

1. Perez RP: Cellular and molecular determinants of cisplatin resistance. Eur J Cancer 34: 1535-1542, 1998.

2. Misset JL, Bleiberg H, Sutherland W, Bekradda M and Cvitkovic E: Oxaliplatin clinical activity: a review. Crit Rev Oncol Hematol 35: 75-93, 2000.

3. Siddik ZH: Cisplatin: mode of cytotoxic action and molecular basis of resistance. Oncogene 22: 7265-7279, 2003.

4. Naredi P, Heath DD, Enns RE and Howell SB: Cross-resistance between cisplatin, antimony potassium tartrate, and arsenite in human tumor cells. J Clin Invest 95: 1193-1198, 1995.

5. Naredi P, Heath DD, Enns RE and Howell SB: Cross-resistance between cisplatin and antimony in a human ovarian carcinoma cell line. Cancer Res 54: 6464-6468, 1994.

6. Silver S: Bacterial resistances to toxic metalions - a review. Gene 179: 9-19, 1996.

7. Lin YF, Walmsley AR and Rosen BP: An arsenic metallochaperone for an arsenic detoxification pump. Proc Natl Acad Sci USA 103: 15617-15622, 2006.

8. Bhattacharjee H, Ho YS and Rosen BP: Genomic organization and chromosomal localization of the Asnal gene, a mouse homologue of a bacterial arsenic-translocating ATPase gene. Gene 272: 291-299, 2001.

9. Kurdi-Haidar B, Aebi S, Heath D, et al: Isolation of the ATPbinding human homolog of the arsA component of the bacterial arsenite transporter. Genomics 36: 486-491, 1996.

10. Kurdi-Haidar B, Heath D, Aebi S and Howell SB: Biochemical characterization of the human arsenite-stimulated ATPase (hASNA-I). J Biol Chem 273: 22173-22176, 1998.

11. Tseng YY, Yu CW and Liao VH: Caenorhabditis elegans expresses a functional ArsA. FEBS J 274: 2566-2572, 2007.

12. Kurdi-Haidar B, Hom DK, Flittner DE, et al: Dual cytoplasmic and nuclear distribution of the novel arsenite-stimulated human ATPase (hASNA-I). J Cell Biochem 71: 1-10, 1998.

13. Kurdi-Haidar B, Heath D, Naredi P, Varki N and Howell SB: Immunohistochemical analysis of the distribution of the human ATPase (hASNA-I) in normal tissues and its overexpression in breast adenomas and carcinomas. J Histochem Cytochem 46: 1243-1248, 1998.

14. Kao G, Nordenson C, Still M, Ronnlund A, Tuck S and Naredi P: ASNA-1 positively regulates insulin secretion in c.elegans and mammalian cells. Cell 128: 577-587, 2007.

15. Mukhopadhyay R, Ho YS, Swiatek PJ, Rosen BP and Bhattacharjee H: Targeted disruption of the mouse Asnal gene results in embryonic lethality. FEBS Lett 580: 3889-3894, 2006.

16. Hemmingsson O, Zhang Y, Still M and Naredi P: ASNA1, an ATPase targeting tail-anchored proteins, regulates melanoma cell growth and sensitivity to cisplatin and arsenite. Cancer Chemother Pharmacol 63: 491-499, 2009.

17. Schuldiner M, Metz J, Schmid V, et al: The GET complex mediates insertion of tail-anchored proteins into the ER membrane. Cell 134: 634-645, 2008.

18. Stefanovic S and Hegde RS: Identification of a targeting factor for posttranslational membrane protein insertion into the ER. Cell 128: 1147-1159, 2007.

19. Favaloro V, Spasic M, Schwappach B and Dobberstein B: Distinct targeting pathways for the membrane insertion of tailanchored (TA) proteins. J Cell Sci 121: 1832-1840, 2008. 
20. Mishima M, Samimi G, Kondo A, Lin X and Howell SB: The cellular pharmacology of oxaliplatin resistance. Eur J Cancer 38: $1405-1412,2002$.

21. Katano K, Kondo A, Safaei R, et al: Acquisition of resistance to cisplatin is accompanied by changes in the cellular pharmacology of copper. Cancer Res 62: 6559-6565, 2002

22. Samimi G, Katano K, Holzer AK, Safaei R and Howell SB: Modulation of the cellular pharmacology of cisplatin and its analogs by the copper exporters ATP7A and ATP7B. Mol Pharmacol 66: 25-32, 2004.

23. Holzer AK, Katano K, Klomp LW and Howell SB: Cisplatin rapidly down-regulates its own influx transporter hCTR1 in cultured human ovarian carcinoma cells. Clin Cancer Res 10: 6744-6749, 2004.

24. Shen J, Hsu CM, Kang BK, Rosen BP and Bhattacharjee H: The Saccharomyces cerevisiae Arr4p is involved in metal and heat tolerance. Biometals 16: 369-378, 2003.

25. DiSaia PJ, Sinkovics JG, Rutledge FN and Smith JP: Cellmediated immunity to human malignant cells. A brief review and further studies with two gynecologic tumors. Am J Obstet Gynecol 114: 979-989, 1972.

26. Mosmann T: Rapid colorimetric assay for cellular growth and survival: application to proliferation and cytotoxicity assays. J Immunol Methods 65: 55-63, 1983

27. Koonin EV: A superfamily of ATPases with diverse functions containing either classical or deviant ATP-binding motif. J Mol Biol 229: 1165-1174, 1993.
28. Ungermann $C$ and Langosch D: Functions of SNAREs in intracellular membrane fusion and lipid bilayer mixing. J Cell Sci 118: 3819-3828, 2005.

29. Safaei R, Katano K, Larson BJ, et al: Intracellular localization and trafficking of fluorescein-labeled cisplatin in human ovarian carcinoma cells. Clin Cancer Res 11: 756-767, 2005.

30. Adams JM and Cory S: The Bcl-2 apoptotic switch in cancer development and therapy. Oncogene 26: 1324-1337, 2007.

31. Mandic A, Hansson J, Linder S and Shoshan MC: Cisplatin induces endoplasmic reticulum stress and nucleus-independent apoptotic signaling. J Biol Chem 278: 9100-9106, 2003.

32. Hori O, Miyazaki M, Tamatani T, et al: Deletion of SERP1/ RAMP4, a component of the endoplasmic reticulum (ER) translocation sites, leads to ER stress. Mol Cell Biol 26: 4257-4267, 2006.

33. Metz J, Wachter A, Schmidt B, Bujnicki JM and Schwappach B: The yeast Arr4p ATPase binds the chloride transporter Gef1p when copper is available in the cytosol. J Biol Chem 281: 410-417, 2006.

34. Wang D and Lippard SJ: Cellular processing of platinum anticancer drugs. Nat Rev Drug Discov 4: 307-320, 2005.

35. Rabik CA and Dolan ME: Molecular mechanisms of resistance and toxicity associated with platinating agents. Cancer Treat Rev 33: 9-23, 2007. 